\title{
THERMAL INSULATION PERFORMANCE OF FLEXIBLE PIPING FOR USE IN HTS POWER CABLES
}

\author{
J.E. Fesmire ${ }^{a}$, S.D. Augustynowicz ${ }^{b}$, and J.A. Demko ${ }^{c}$ \\ ${ }^{a}$ NASA Kennedy Space Center, YA-F2-T \\ Kennedy Space Center, Florida, 32899, USA \\ ${ }^{b}$ Dynacs Inc., DNX-3 \\ Kennedy Space Center, Florida, 32899, USA \\ ${ }^{\circ}$ Oak Ridge National Laboratory \\ Oak Ridge, Tennessee, 37831, USA
}

\begin{abstract}
High-temperature superconducting (HTS) cables that typically operate at temperatures below 80 kelvin $(\mathrm{K})$ are being developed for power transmission. The practical application of HTS power cables will require the use of flexible piping to contain the cable and the liquid nitrogen coolant. A study of thermal performance of multilayer insulation (MLI) was conducted in geometries representing both rigid and flexible piping. This experimental study performed at the Cryogenics Test Laboratory of NASA Kennedy Space Center provides a framework for the development of cost-effective, efficient thermal insulation systems that will support these long-distance flexible lines containing HTS power cables. The overall thermal performance of the insulation system for a rigid configuration and for a flexible configuration, simulating a flexible HTS power cable, was determined by the steady-state liquid nitrogen boiloff method under the full range of vacuum levels. Two different cylindrically rolled material systems were tested: a standard MLI and a layered composite insulation (LCI). Comparisons of ideal MLI, MLI on rigid piping, and MLI between flexible piping are presented.
\end{abstract}

\section{INTRODUCTION}

Thermal losses are a key factor in the successful application of HTS power cables. Existing concepts and prototypes rely on the use of MLI that is subject to large variations in actual performance. The small space available for the thermal insulation materials makes 
the application even more difficult because of bending considerations, mechanical loading, and the arrangement between the inner and outer piping. Each of these mechanical variables affects the heat leak rate. These factors of bending and spacing are examined in part two of this study [1]. Furthermore, a maintenance-free insulation system (high-vacuum level for 20 years or longer) is a practical requirement. A thermal insulation system simulating a section of a flexible HTS power cable was constructed for test and evaluation on a research cryostat. This paper gives experimental data for the comparison of ideal MLI, MLI on rigid piping, and MLI between flexible piping. The section of flexible piping consists of an inner and an outer corrugated metal hose (or bellows) with no spacers.

\section{EXPERIMENTAL}

The liquid nitrogen boiloff method utilizing a cylindrical cryostat was used for all tests. This cryostat is a liquid nitrogen boiloff calorimeter apparatus for direct measurement of the apparent thermal conductivity (k-value) of a material system at a fixed vacuum level [2]. The configuration includes a 910-millimeter- $(\mathrm{mm})$ long cylindrical cold mass with liquid nitrogen guard chambers. Continuously rolled insulation materials are installed onto the inner bellows or smooth sleeve using a custom wrapping machine. Sensors are placed between layers of the insulation to obtain temperature-thickness profiles. The inner bellows or smooth sleeve with insulation installed is slid onto the vertical cold mass of the cryostat. The outer bellows is then put into place as depicted in FIGURE 1. The cold vacuum pressure (CVP) is adjusted for the desired vacuum level. Test articles are heated and evacuated to below $10^{-4}$ torr to begin a test series. The residual gas is nitrogen for all tests.

The temperatures of the cold mass, inner bellows [cold boundary temperature (CBT)], insulation layers, outer bellows [warm boundary temperature (WBT)], and vacuum chamber are measured as shown in FIGURE 1. When the vacuum level, all temperatures, and the boiloff flow are stable, the k-value is determined from Fourier's law of heat conduction for a cylindrical wall as given by equation (1):

$$
k \text {-value }=\frac{\dot{m} h_{f g} \ln \frac{D_{o}}{D_{i}}}{2 \pi L_{e f f}\left(T_{o}-T_{i}\right)}
$$

where:

$$
\begin{aligned}
& T_{o}=\text { WBT, } \mathrm{K} \\
& T_{i}=\mathrm{CBT}, \mathrm{K} \\
& D_{o}=\text { outer bellows mean diameter, millimeter }(\mathrm{mm}) \\
& D_{i}=\text { inner bellows mean diameter, } \mathrm{mm} \\
& L_{e f f}=\text { effective length of cold mass test chamber, meter }(\mathrm{m}) \\
& m=\text { boiloff flow rate, gram per second }(\mathrm{g} / \mathrm{s}) \\
& h_{f g}=\text { heat of vaporization, joule per gram }(\mathrm{J} / \mathrm{g})
\end{aligned}
$$

The $\mathrm{k}$-value is the apparent thermal conductivity for the total insulation system, in milliwatts per meter-kelvin $(\mathrm{mW} / \mathrm{m}-\mathrm{K})$. A thermal shroud on the vacuum chamber kept the WBT at approximately $293 \mathrm{~K}$ while the liquid nitrogen cold mass maintained the CBT at approximately $90 \mathrm{~K}$. 


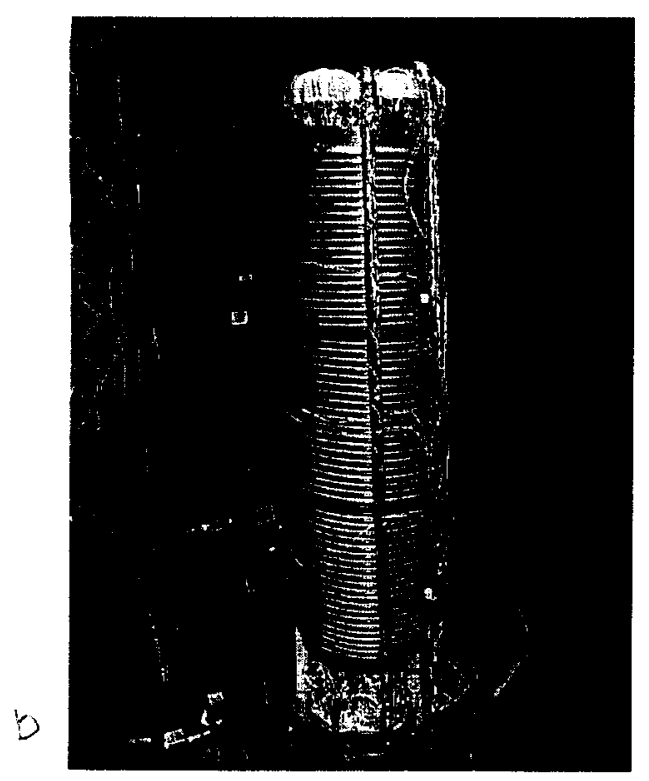

FIGURE 1. (a) Diagram showing configuration of corrugated piping and location of temperature sensors. (b) View of test apparatus with vacuum chamber removed showing outer corrugated pipe.

Both of the 900-mm-overall-length bellows are constructed from 0.51-mm-thick series 321 stainless steel. The convolutions are u-shaped with a $12.7-\mathrm{mm}$ pitch and a depth of $12.7 \mathrm{~mm}$ (outer) and $15.9 \mathrm{~mm}$ (inner). The standard diameters for the bellows are: 254 $\mathrm{mm}$ by $279 \mathrm{~mm}$ (outer) and $168 \mathrm{~mm}$ by $200 \mathrm{~mm}$ (inner). The insulation space, or gap, between the inside diameter of the outer bellows and the outside diameter of the inner bellows defines the geometry for the k-value calculation.

\section{RESULTS AND DISCUSSION}

Over 40 tests of 5 different thermal insulation systems were performed for this part of the research study. TABLE 1 reports the key measurements and conditions for the insulation test articles. The benchmark MLI systems (C108 with 40 layers and C123 with 60 layers) are in good agreement with the experimental data for similar systems as reported by Kaganer [3], Hnilicka [4], and Black [5]. The Kaganer line is for the following system: aluminum foil and fiberglass spacer, 1.5 layers per mm, 293 and $90 \mathrm{~K}$ boundary temperatures, and air as residual gas. The overall summary graph of the apparent thermal conductivity as a function of CVP is presented in FIGURE 2.

The curves for MLI on smooth-sleeve configurations are denoted by $\mathrm{C} 108$ and $\mathrm{C} 123$. At the high-vacuum region of main interest, $\mathrm{C} 108$ is slightly better (lower k-value) than $\mathrm{C} 123$, which can be attributed to its lower layer density. The net heat transfer through MLI is known to increase with both layer density and the number of layers above a particular lower limit. For example, Bapat et al. show this trend for similar materials and conditions reporting a k-value of $0.0827 \mathrm{~mW} / \mathrm{m}-\mathrm{K}$ for 60 layers at a density of 2.810 layers per $\mathrm{mm}$ [6]. The Kaganer line with a $\mathrm{k}$-value of $0.05 \mathrm{~mW} / \mathrm{m}-\mathrm{K}$ represents the best possible thermal performance under ideal laboratory conditions. The LCI system, C107, shows comparable performance at high vacuum and superior performance at vacuum levels above $10^{-2}$ torr. The data for $\mathrm{C} 107$ and $\mathrm{C} 108$, shown here for reference, were previously reported [7]. 
Figure $3 a$.

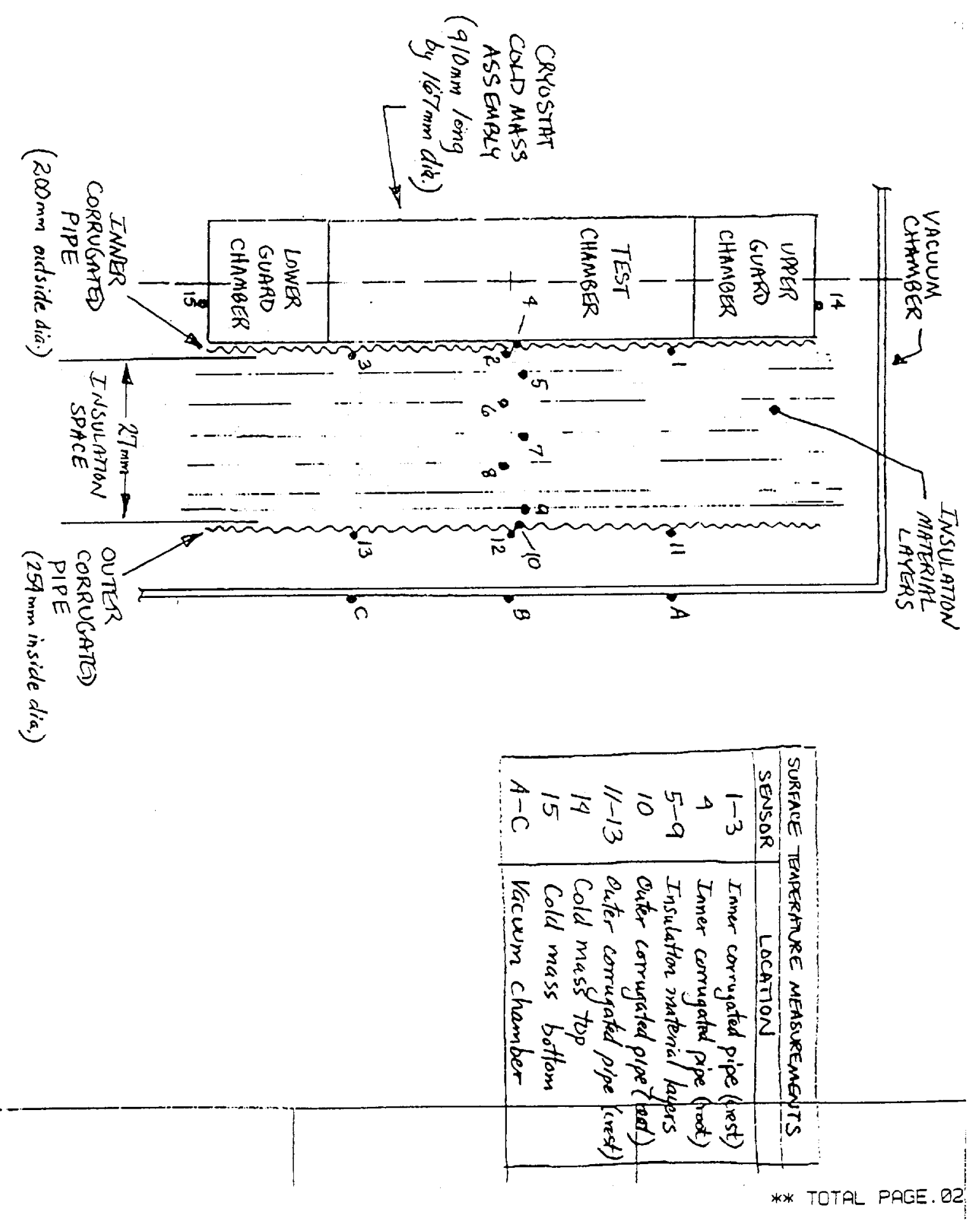


TABLE 1. Summary of measurements and conditions for insulation test articles.

\begin{tabular}{|c|c|c|c|c|c|c|c|}
\hline $\begin{array}{l}\text { Test } \\
\text { No. }\end{array}$ & $\begin{array}{l}\text { Description } \\
\text { of } \\
\text { Insulation } \\
\text { System }\end{array}$ & $\begin{array}{c}\text { Installed } \\
\text { Density } \\
\left(\mathbf{k g} / \mathbf{m}^{3}\right)^{*}\end{array}$ & $\begin{array}{l}\text { Total } \\
\text { Thick- } \\
\text { ness } \\
\text { (mm) }\end{array}$ & $\begin{array}{c}\text { CVP } \\
\text { (mil- } \\
\text { liTorr) }\end{array}$ & $\begin{array}{l}\text { k- } \\
\text { value } \\
(\mathrm{mW} / \\
\mathrm{m}-\mathrm{K})\end{array}$ & $\begin{array}{c}\text { CBT } \\
(\mathbf{K})\end{array}$ & $\begin{array}{c}\text { WBT } \\
(\mathrm{K})\end{array}$ \\
\hline $\begin{array}{l}\text { C107 } \\
\text { (ref.) }\end{array}$ & $\begin{array}{l}\text { Smooth sleeve, } \\
\text { layered compos- } \\
\text { ite insulation, } \\
18 \text { lavers }\end{array}$ & 52 & 24.8 & $\begin{array}{l}0.05 \\
10 \\
1000\end{array}$ & $\begin{array}{l}0.09 \\
0.49 \\
2.60\end{array}$ & $\begin{array}{l}91 \\
88 \\
90\end{array}$ & $\begin{array}{l}281 \\
279 \\
269\end{array}$ \\
\hline $\begin{array}{l}\text { C108 } \\
\text { (ref.) }\end{array}$ & $\begin{array}{l}\text { Smooth sleeve, } \\
\text { MLI, aluminum } \\
\text { foil and fiber- } \\
\text { glass paper, } 40 \\
\text { layers, } 1.8 \text { lay- } \\
\text { ers } / \mathrm{mm}\end{array}$ & 58 & 22.3 & $\begin{array}{l}0.2 \\
10 \\
1000\end{array}$ & $\begin{array}{l}0.08 \\
0.488 \\
9.49\end{array}$ & $\begin{array}{l}87 \\
90 \\
92\end{array}$ & $\begin{array}{l}281 \\
256 \\
196\end{array}$ \\
\hline$\overline{\mathrm{C} 123}$ & $\begin{array}{l}\text { Smooth sleeve, } \\
\text { MLI, aluminum } \\
\text { foil and fiber- } \\
\text { glass paper, } 60 \\
\text { layers, } 2.4 \text { lay- } \\
\text { ers/mm }\end{array}$ & 79 & 24.5 & $\begin{array}{c}0.01 \\
10 \\
1000\end{array}$ & $\begin{array}{l}0.09 \\
0.48 \\
9.96\end{array}$ & & \\
\hline $\mathrm{C} 125$ & $\begin{array}{l}\text { Corrugated in- } \\
\text { ner pipe and } \\
\text { corrugated outer } \\
\text { pipe, no insula- } \\
\text { tion material }\end{array}$ & $\mathrm{N} / \mathrm{A}^{* *}$ & $\begin{array}{l}\text { N/A } \\
27.0 \\
\text { (gap) }\end{array}$ & $\begin{array}{c}0.01 \\
10\end{array}$ & $\begin{array}{l}17.7 \\
22.5\end{array}$ & & \\
\hline C119 & $\begin{array}{l}\text { Corrugated, } \\
\text { MLI, aluminum } \\
\text { foil and fiber- } \\
\text { glass paper, } 60 \\
\text { layers, } 2.5 \text { lay- } \\
\text { ers } / \mathrm{mm}\end{array}$ & 82 & $\begin{array}{l}23.8 \\
27.0 \\
\text { (gap) }\end{array}$ & $\begin{array}{c}0.01 \\
10 \\
1000\end{array}$ & $\begin{array}{l}0.19 \\
0.72 \\
8.49\end{array}$ & & \\
\hline C131 & $\begin{array}{l}\text { Corrugated, } \\
\text { MLI, aluminum } \\
\text { foil and fiber- } \\
\text { glass paper, } 60 \\
\text { layers, } 2.2 \text { lay- } \\
\text { ers } / \mathrm{mm}\end{array}$ & 72 & $\begin{array}{l}27.0 \\
27.0 \\
\text { (gap) }\end{array}$ & $\begin{array}{l}0.01 \\
10 \\
1000\end{array}$ & $\begin{array}{l}0.12 \\
0.45 \\
8.06\end{array}$ & & \\
\hline $\mathrm{C} 127$ & $\begin{array}{l}\text { Corrugated, } \\
\text { layered compos- } \\
\text { ite insulation, } \\
30 \text { layers }\end{array}$ & 78 & $\begin{array}{l}23.0 \\
27.0 \\
\text { (gap) }\end{array}$ & $\begin{array}{c}0.02 \\
10 \\
1000\end{array}$ & $\begin{array}{l}0.20 \\
0.59 \\
3.05\end{array}$ & & \\
\hline
\end{tabular}

${ }^{*} \mathrm{~kg} / \mathrm{m}^{3}$ : kilogram per cubic meter

The curves for MLI between corrugated piping are denoted by C119 and C131. The kvalues are from 30 to 120 percent higher at high vacuum compared to the smooth sleeve MLI of test series C123. Performance for all MLI types is shown to converge near 10 $\mathrm{mW} / \mathrm{m}-\mathrm{K}$ at soft vacuum (1 torr). Test series $\mathrm{C} 127$, which includes the LCI rather than MLI between the corrugated piping, shows comparable performance at high vacuum and about three times lower $\mathrm{k}$-value $(3 \mathrm{~mW} / \mathrm{m}-\mathrm{K})$ at 1 torr CVP. In addition, test series $\mathrm{C} 125$ provides the reference case for the corrugated piping by itself with no insulation between the inner and outer bellows. The high heat flux measured in this case shows the dramatically poor insulation effect that vacuum alone can provide. Analysis of the radiation heat transfer between concentric corrugated pipes to isolate the effect of the corrugations on the overall thermal performance of the total insulation system is examined in the next section. 
FIGURE 2. Variation of apparent thermal conductivity (k-value) with cold vacuum pressure (CVP).

\begin{abstract}
ANALYSIS
The test geometry without any insulation, such as in test series C125, can be analyzed as a four-surface enclosure consisting of a cold inner cylinder and a warm outer cylinder that are closed off at the ends by annular rings. For high vacuum, the heat transfer is by thermal radiation alone. The analysis has been performed using the unified method for radiation calculations as described in Gebhart [8], which is sometimes referred to as Gebhart's method. In Gebhart's method, absorption factors, $B_{i j}$, are developed for each surface based on the enclosure geometry and surface emissivity, which are the total fraction of the thermal energy emitted from a given surface, $i$, that is absorbed by another surface, $j$, in the enclosure. Equation (2) gives the net rate of radiation heat transfer from the jth surface:
\end{abstract}

$$
q_{j}=\sigma A_{j} \varepsilon_{j} T_{j}^{4}-\sum_{i=1}^{4} B_{i, j} \sigma A_{i} \varepsilon_{i} T_{i}^{4}
$$

In this equation, $\sigma$ is the Stefan-Boltzmann constant, $A$ is the surface area, $T$ is the surface temperature, and $\varepsilon$ is the surface emissivity.

The method has been applied to measured data from test of the stainless-steel (SST) vacuum chamber (the warm outer surface), the bare SST cold mass, and the cold mass with a copper sleeve. The measured parameters are the temperatures of the inner and outer surfaces and the heat load. The unknown quantities to the heat transfer analysis are the surface emissivities obtained by trial and error through successive application of the four-surface enclosure analysis. Results are shown in FIGURE 3 for the surface emissivities determined here, which are in agreement with other published emissivity data for the same materials. 
-ig. 2

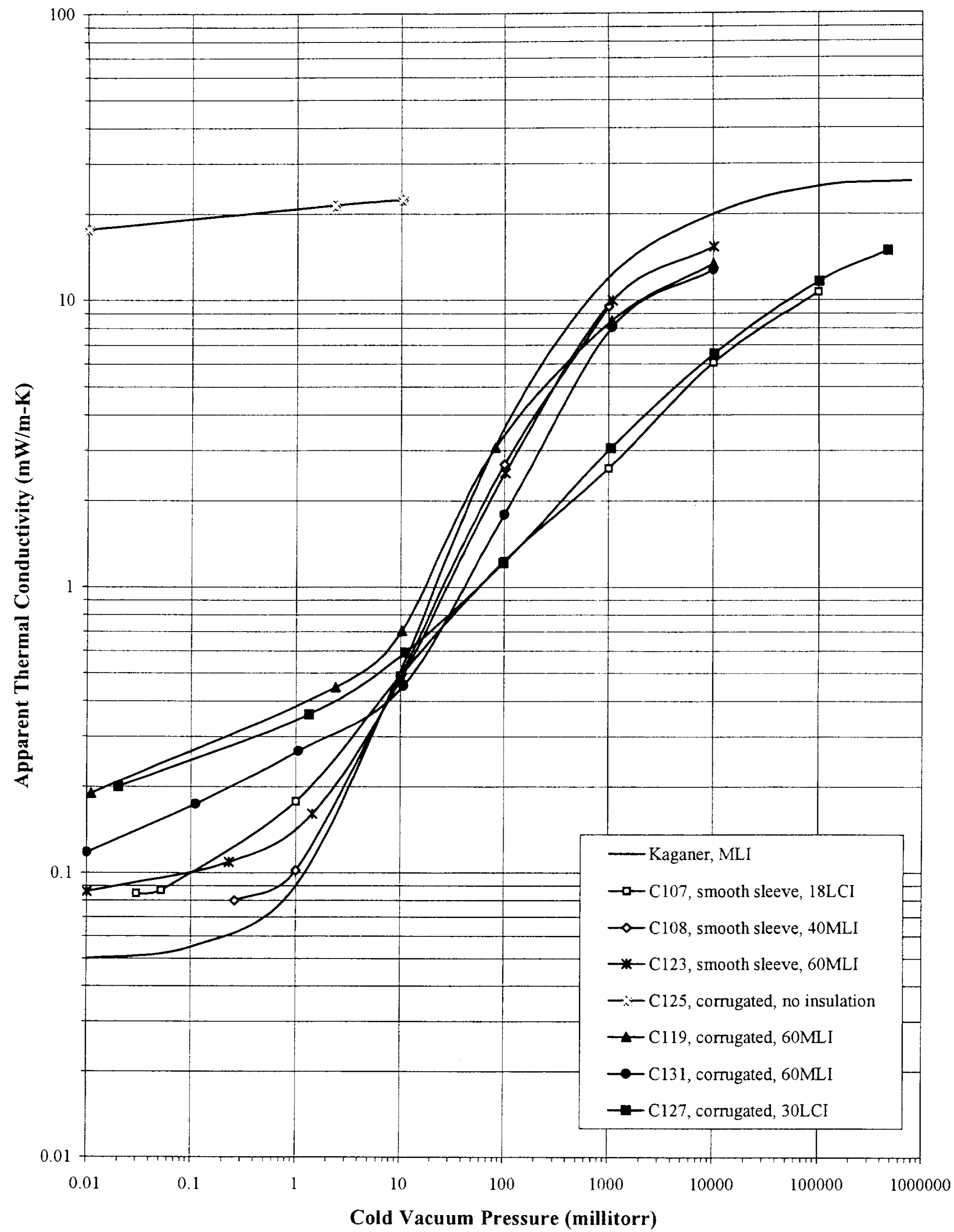




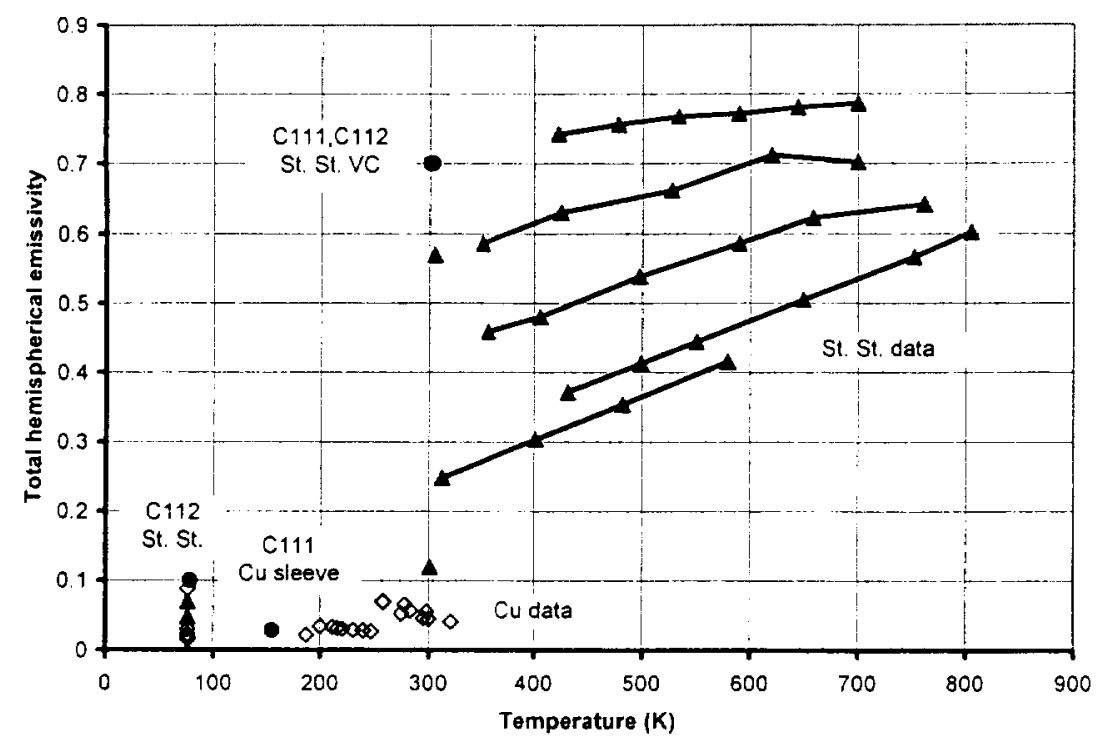

FIGURE 3 - Comparison of emissivities from handbook values for SST $(\wedge)$ and copper $(\diamond)$ with those from experiments with insulation test cryostat for SST vacuum chamber, SST cold mass, and cold mass copper sleeve.

For corrugated pipe, the Gebhart enclosure thermal radiation method shows enhanced heat transfer due to the larger surface area. An enclosure is assumed to be formed from a single corrugation and an imaginary cylindrical surface with a diameter equal to the inside of the corrugated cylinder. A single corrugation and the cylinder are illustrated in FIGURE 4. The corrugation, surface 1 , has an area larger than the cylindrical surface 2 . The corrugation radiates to itself and the cylinder, while the cylinder radiates only to the corrugation. Hence the view factor of the cylinder to the corrugation is unity, and all others can be determined by view factor algebra. From the view factors and assuming reasonable values for the surface emissivity, the four necessary absorption factors can be obtained. This arrangement resembles the ideal use of MLI that completely fills the gap between a doublewalled, flexible pipe.

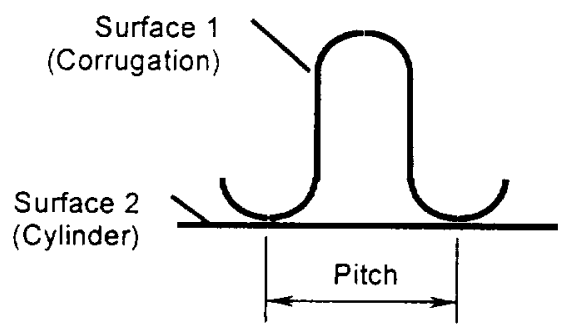

FIGURE 4. Typical geometry of corrugation surface.

Three cases were analyzed to show the effect of corrugation size on heat transfer: (1) both surfaces are highly emitting, (2) the corrugation is highly emitting and the cylinder representing the outer reflector layer is highly reflecting, and (3) both surfaces are highly reflecting. Case 2 represents the most common situation with a stainless-steel corrugated outer pipe, with no special surface treatment or polishing, next to a reflective layer. Case 3 represents a corrugated pipe that is polished on the inside to increase its surface reflectance. The analysis was conducted by calculating the ratio of heat flux of the cylinder with the area of surface 1 greater than the area of surface 2 (or $q_{\text {corrug }}$ ) to the heat transfer when they are both equal in area (or $\mathrm{q}_{\mathrm{ref}}$ ). The ratio depends only on the geometry and surface emis- 
sivity. TABLE 2 provides results for $A_{1} / A_{2}=2.0$ using heat fluxes based on the corrugations at $300 \mathrm{~K}$ and the cylinder at $290 \mathrm{~K}$. An order of magnitude reduction in heat transfer by having a reflective cylindrical surface is shown in TABLE 2. An additional 30-percent reduction in heat transfer can be obtained by polishing the inner surface of the corrugated outer tube. The variation of the thermal radiation factor with area ratio is provided in FIGURE 5 for the same three cases. The results show the emitting corrugation does not significantly enhance the thermal radiation to a reflecting inner surface. However, when both surfaces are either emitting or reflecting, there is a greater dependence of the thermal radiation heat transfer on the surface area.

Table 2. Predicted heat flux for three different cases of surfaces.

\begin{tabular}{|l|c|c|c|c|c|}
\hline \multicolumn{1}{|c|}{ Type of Surface } & $\varepsilon_{1}$ & $\varepsilon_{2}$ & $\begin{array}{c}\mathbf{q}_{\text {ref }} \\
\left(\mathbf{W} / \mathbf{m}^{2}\right)\end{array}$ & Factor & $\begin{array}{c}\mathbf{q}_{\text {corrug }} \\
\left(\mathbf{W} / \mathbf{m}^{2}\right)\end{array}$ \\
\hline Both highly emitting & 0.70 & 0.70 & 31.38 & 1.13 & 35.45 \\
\hline $\begin{array}{l}\text { Corrugation emitting to reflecting } \\
\text { surface }\end{array}$ & 0.70 & 0.07 & 3.96 & 1.01 & 4.00 \\
\hline Both highly reflecting & 0.07 & 0.07 & 2.11 & 1.32 & 2.79 \\
\hline
\end{tabular}

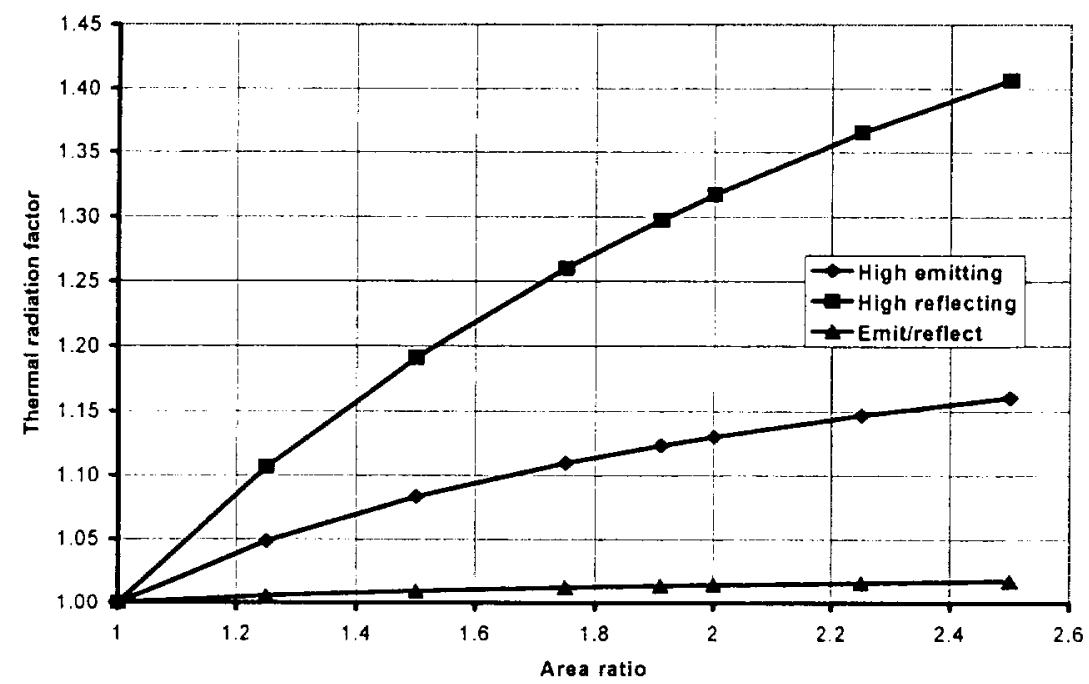

FIGURE 5. The effect of corrugation geometry on the radiation heat transfer for three cases.

\section{CONCLUSIONS}

The results of this experimental research study of flexible piping for HTS power cables show three basic levels of thermal performance: ideal MLI, MLI on rigid piping, and MLI between flexible piping. Standard diameters of the inner and outer flexible piping were used to compute the apparent thermal conductivity (k-value) so that reasonable comparisons of different pipelines under similar cryogenic conditions can be made.

The performance of ideal MLI is defined as a k-value of $0.05 \mathrm{~mW} / \mathrm{m}-\mathrm{K}$, for a vacuum level below 0.1 micron and boundary temperatures of approximately $80 \mathrm{~K}$ and $293 \mathrm{~K}$, based on experimental results from the literature. At a high vacuum level, the k-values of MLI on rigid piping were about $0.09 \mathrm{~mW} / \mathrm{m}-\mathrm{K}$ ( 80 percent higher than the ideal MLI). Under similar conditions, the k-values of MLI between flexible piping were 0.12 to 0.20 
$\mathrm{mW} / \mathrm{m}-\mathrm{K}$ (from 30 to 120 percent higher than the $\mathrm{k}$-values for MLI on rigid piping). The new layered composite insulation, on the smooth sleeve or between the corrugated piping, performed as well as MLI at high vacuum and much better than MLI at soft vacuum.

Analysis of radiation effects showed the corrugations could be a source of an increased rate of heat transfer relative to the rigid piping. Polishing the inner wall can make significant reductions to the heat transfer in vacuum insulated lines. Work on material optimization and application design is currently planned for the Cryogenics Test Laboratory at NASA Kennedy Space Center. The target is to be able to make flexible piping with thermal performance approaching that of rigid piping to help make energy-efficient HTS power cables become an industrial reality.

\section{ACKNOWLEDGEMENTS}

The authors thank Mr. Wayne Heckle and Mr. Zoltan Nagy of Dynacs Inc. for their assistance in performing the experiments.

This work was supported by the U.S. Department of Energy by interagency agreement DE-AI05-00OR22814 under the Superconductivity Partnership Initiative.

\section{REFERENCES}

1. Fesmire, J.E., Augustynowicz, S.D., and Demko, J.A., "Overall Thermal Performance of Flexible Piping Under Simulated Bending Conditions," Cryogenic Engineering Conference, Madison, July 2001.

2. Fesmire, J.E. and Augustynowicz, S.D., "Insulation Testing Using Cryostat Apparatus With Sleeve," in Advances in Cryogenic Engineering, Vol. 45, Kluwer Academic/ Plenum Publishers, New York, 2000 , pp. 1683-1690.

3. Kaganer, M.G., "Thermal Insulation in Cryogenic Engineering," in Israel Program for Scientific Translations, Inc., IPST Press, Jerusalem, 1969, pp. 114-116.

4. Hnilicka, M.P., "Engineering Aspects of Heat Transfer in Multilayer Reflective Insulation and Performance of NRC Insulation," in Advances in Cryogenic Engineering, Vol. 5, Plenum Press, New York, 1960 , pp. 199-208.

5. Black, I.A. and Glaser, P.E., "Progress Report on the Development of High-Efficiency Insulation," in Advances in Cryogenic Engineering, Vol. 6, Plenum Press, New York, 1960, pp. 32-41.

6. Bapat, S.L., Narayankhedkar, K.G., and LuKose, T.P., "Experimental Investigations of Multilayer Insulation," Cryogenics, Vol. 30, 1990, pp. 711-719.4.

7. Augustynowicz, S.D. and Fesmire, J.E., "Cryogenic Insulation System for Soft Vacuum," in Advances in Cryogenic Engineering, Vol. 45, Kluwer Academic/Plenum Publishers, New York, 2000, pp. 1691-1698.

8. Gebhart, B., Heat Transfer, McGraw-Hill Book Co., New York, 1961, pp. 117-120. 